\title{
Norman M. Bradburn: A Pioneer in Social Indicators and Quality of Life Research
}

\author{
Norman M. Bradburn ${ }^{1,2}$
}

Received: 10 January 2016/Accepted: 17 January 2016 /Published online: 25 January 2016 (C) Springer Science+Business Media Dordrecht and The International Society for Quality-of-Life Studies (ISQOLS) 2016

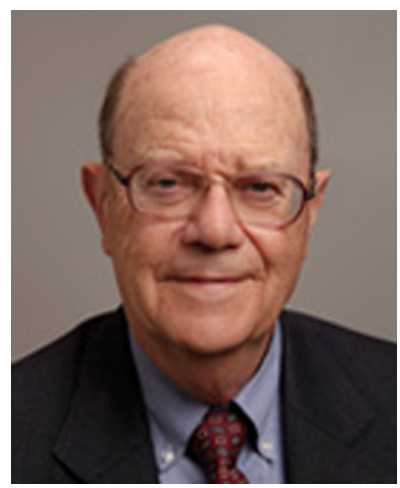

I was born in Lincoln, Illinois. My father was a small-town doctor. His father was a doctor in the same town. It is one of those stories of growing up in a town where everybody knows you. But that all came to an end with the Second World War, and my father went into the army as an army doctor. So beginning in 1942, my mother and brother and I began to live a life of moving around, back and forth between Lincoln and other places, depending on where he was. My father died shortly after the war. We then moved to Nashville, Tennessee, where I went to high school. I went to the University of Chicago, Harvard and Oxford and got an incredibly broad education in the social sciences and humanities.

I was interested in so many fields I could not decide what I wanted to study but finally decided on getting a $\mathrm{PhD}$ in clinical psychology, although I hedged my bets by

\section{Norman M. Bradburn}

bradburn-norman@norc.org

1 University of Chicago, Chicago, IL, USA

2 NORC at the University of Chicago, Chicago, IL, USA 
enrolling in the Harvard Social Relations Department, where I could study social psychology, sociology and anthropology in addition to clinical psychology. In the event, I decided I was not cut out to be a clinician, so after completing my masters in clinical, I transferred to the social psychology program. I did a dissertation on entrepreneurship in Turkey as a part of a large multi-nation study on psychological factors in economic development. The dissertation brought together various strands of my study at Oxford in philosophy, politics and economics, and my new work in social psychology, particularly the study of McClelland's concept of need Achievement.

After graduation I took a job as an assistant professor in the University of Chicago's Business School which was developing an interdisciplinary program in economic development. Through a chance connection I had an opportunity to develop a research program at the National Opinion Research Center (NORC), a research affiliate of the University of Chicago, in economic factors in mental health.

At the time (early 1960s) there was a nascent movement for population-based studies of mental health, but these depended on traditional measures of psychiatric symptoms. Our study shifted from a focus on symptoms of mental illness to a focus on positive functioning and the investigation of the interplay between everyday experiences and psychological and social well-being. In the course of developing the measures for the study we discovered that our measures of positive affect and of negative affect were statistically independent from one another but each was related in the expected direction to overall evaluative measures such as self-reported happiness and life satisfaction. The work is described in my 1969 book The Structure of Psychological Well-Being. In these studies we developed the Affect Balance Scale (ABS) which measured positive and negative affect independently, but when combined were strongly related to measures of evaluative well-being. This was a major new finding but was rejected by many psychologists who believed that positive and negative emotions had to be the opposite ends of a single dimension rather than two independent dimensions. For many years the apparent independence of the two measures was viewed as some sort of artifact of the particular measures we used. I am happy that the independence of the dimensions has now been replicated many times and is now accepted as a basis for studying hedonic well-being. The ABS has been used in many studies, both in the U.S. and in other countries and, even after 50 years is still widely used.

Because of a lack of general interest in positive psychological functioning at the time and because many of the critiques of the ABS and the independence of the two dimensions were largely based on hypotheses about measurement artifacts, my interest turned to the study of errors in measurement in self-reports. This led me away from further substantive work in well-being into a career that has been involved with applying concepts from cognitive psychology to survey methodology. I have been fortunate in having the opportunity to be a pioneer in another field and to help stimulate the development of a new approach to developing questionnaires in scientific surveys. My work in both of these areas was recognized in 1985 by the Helen Dinerman Award of the World Association for Public Opinion Research. More recently, in 2004, I was given the Statistics Canada / American Statistical Association Waksberg Award in recognition of outstanding contributions to the theory and practice of survey methodology.

I did not abandon all interest in the well-being research and followed the research of my former student and colleague Mihaly Csikszentmihalyi and that of Ed Diener, 
whom I met through a mutual colleague, Seymour Sudman, at the University of Illinois. They kept research on psychological well-being going even when there was little interest among psychologists in the field. I am pleased that after some years of neglect, the field of subjective well-being has become a robust area of study and am honored to be considered a pioneer in its development. I do find it a bit ironic that much of its current popularity comes from the enthusiasm that some economists have shown for the study of subjective well-being. I don't think I would have gotten tenure as the University of Chicago for my early work on happiness if my appointment had been in the Psychology Department rather than the Business School. Even in the 60s economists were delighted to find positive relationships between economic variables and subjective well-being. My peculiar background in both economics and psychology found a congenial home there.

\section{Selected References}

Bradburn, N. M. (1969). The structure of psychological well-being. Chicago: Aldine. 